\title{
Disproportionally Impaired Diffusion Capacity Relative to Airflow Limitation in COPD
}

\section{$\operatorname{AUTHOR}(\mathrm{S})$ :}

Tanabe, Naoya; Rhee, Chin Kook; Sato, Susumu; Muro, Shigeo; Shima, Hiroshi; Tanimura, Kazuya; Jung, Ki-Suck; Yoo, Kwang Ha; Hirai, Toyohiro

\section{CITATION:}

Tanabe, Naoya ... [et al]. Disproportionally Impaired Diffusion Capacity Relative to Airflow Limitation in COPD. COPD: Journal of Chronic Obstructive Pulmonary Disease 2020, 17(6): 627-634

\section{ISSUE DATE:}

\section{0-11-23}

URL:

http://hdl.handle.net/2433/262708

\section{RIGHT:}

This is an Accepted Manuscript of an article published by Taylor \& Francis in 'COPD: Journal of Chronic Obstructive Pulmonary Disease' on 2020, available online: https://www.tandfonline.com/10.1080/15412555.2020.1845639; The fulltext file will be made open to the public on 23 Nov 2021 in accordance with publisher's 'Terms and Conditions for SelfArchiving'; This is not the published version. Please cite only the published version.この論文は出版社版でありません。 引用の際には出版社版をご確認ご利用ください。 
1 Disproportionally impaired diffusion capacity relative to airflow limitation in

2 COPD

3

4 Naoya Tanabe ${ }^{1^{* \dagger}}$, Chin Kook Rhee ${ }^{2 *}$, Susumu Sato ${ }^{1}$, Shigeo Muro ${ }^{1,3}$, Hiroshi Shima ${ }^{1}$,

5 Kazuya Tanimura ${ }^{1}$, Ki-Suck Jung ${ }^{4}$, Kwang Ha Yoo ${ }^{5}$, Toyohiro Hirai ${ }^{1}$

6

$7{ }^{1}$ Department of Respiratory Medicine, Graduate School of Medicine, Kyoto University,

8 Kyoto, Japan

$9 \quad 2$ Division of Pulmonary, Allergy and Critical Care Medicine, Department of Internal

10 Medicine, Seoul St. Mary’s Hospital, College of Medicine, The Catholic University of

11 Korea, Seoul, Republic of Korea

$12{ }^{3}$ Department of Respiratory Medicine, Nara Medical University, Nara, Japan

$13{ }^{4}$ Division of Pulmonary, Allergy and Critical Care Medicine, Department of Internal

14 Medicine, Hallym University Medical Center, Hallym University College of Medicine,

15 Anyang, Republic of Korea

$16{ }^{5}$ Division of Pulmonary, Allergy and Critical Care Medicine, Department of Internal

17 Medicine, Konkuk University School of Medicine, Seoul, Republic of Korea

19 *These two authors contributed equally to this study.

20

21 E-mail Addresses

22 Naoya Tanabe ntana@kuhp.kyoto-u.ac.jp

23 Chin Kook Rhee chinkook77@gmail.com 
24 Susumu Sato ssato@kuhp.kyoto-u.ac.jp

25 Shigeo Muro smuro@naramed-u.ac.jp

26 Hiroshi Shima hirocima2469@kuhp.kyoto-u.ac.jp

27 Kazuya Tanimura kaztani@kuhp.kyoto-u.ac.jp

28 Ki-Suck Jung pulmoks@hallym.ac.kr

29 Kwang Ha Yoo khyou@kuh.ac.kr

30 Toyohiro Hirai_t_hirai@kuhp.kyoto-u.ac.jp

31

32 Corresponding author full contact details:

33 Name: Naoya Tanabe

34 Address: Department of Respiratory Medicine, Graduate School of Medicine, Kyoto

35 University, 54 Kawahara-cho, Shogoin, Sakyo-ku,

36 Post code: 606-8507

37 City: Kyoto

38 Country: Japan

39 E-mail: ntana@kuhp.kyoto-u.ac.jp

40 
Abstract (250/250)

44 Forced expiratory volume in 1 second $\left(\mathrm{FEV}_{1}\right)$ is a standard physiological index of

45 chronic obstructive pulmonary disease (COPD), but reflects emphysema and vascular

46 abnormalities less sensitively than diffusion capacity for carbon monoxide ( $\left.\mathrm{D}_{\mathrm{LCO}}\right)$. This

47 study tested whether a disproportionally impaired $\mathrm{D}_{\mathrm{LCO}}$ relative to $\mathrm{FEV}_{1}\left(\mathrm{FEV} \mathrm{Z}_{1} \mathrm{z}\right.$-score $>$ -

483 and DLCO $_{\text {z-score } \leq-3)}$ is a common functional COPD phenotype associated with distinct

49 clinical and structural features and the prognosis of two cohorts. The cross-sectional

50 analyses of the Korea COPD Subgroup Study (KOCOSS) cohort (multicenter study in

51 Korea) included 743 males with COPD whose $\mathrm{D}_{\text {LCO }}$ was available. The cross-sectional

52 and longitudinal analyses of the Kyoto University Cohort (single-center study in Japan)

53 included 195 males with COPD who were prospectively followed for 10 years. A

54 disproportionally impaired $\mathrm{D}_{\mathrm{LCO}}$ relative to $\mathrm{FEV}_{1}$ was observed in $29 \%$ and $31 \%$ of

55 patients in the KOCOSS and Kyoto University cohorts, respectively. In the multivariable

56 analysis, the disproportionally impaired DLCO was associated with worse symptoms,

57 shorter 6-minute walking distance, paraseptal and centrilobular emphysema on computed

58 tomography, and reduced arterial oxygen and carbon dioxide pressures compared to the

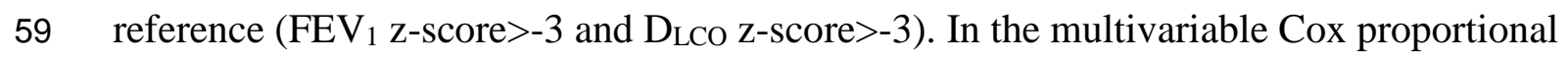

60 hazard model, a higher long-term mortality was observed in the disproportionally

61 impaired $D_{\text {LCO }}$ group than in the reference group (hazard ratio [95\% confidence interval]

$62=3.09$ [1.52-6.29]) and similar to the $\mathrm{D}_{\mathrm{LCO}} \mathrm{z}$-score $\leq-3$ and $\mathrm{FEV}_{1} \mathrm{z}$-score $\leq-3$ group. The

63 disproportionally impaired $\mathrm{D}_{\mathrm{LCO}}$ relative to $\mathrm{FEV}_{1}$ is common and associated with 
64 increased symptoms, emphysema, arterial blood gas abnormalities, and increased long65 term mortality in patients with COPD.

66

67

68 Keywords: Chronic obstructive pulmonary disease, Emphysema, Airway, Computed

69 tomography, Pulmonary function, Prognosis

70

\section{$71 \quad$ Funding}

72 The Kyoto University Cohort was partially supported by the Japan Society for the

73 Promotion of Science (JSPS) [Grants-in-Aid for scientific research 19K08624,

74 16K09536, 25461156, 21590964, and 16390234]. The KOCOSS cohort was funded by

75 Research of Korea Centres for Disease Control and Prevention (2016ER670102 and

76 2018ER670100).

77

78 Declaration of interest statement

79 The authors report no conflicts of interest in this work.

80 


\section{Introduction}

84 Chronic obstructive pulmonary disease (COPD) is a leading cause of death worldwide.[1]

85 While the diagnosis of COPD is simply based on airflow limitation on spirometry,[2] spirometry is insufficient to capture the heterogeneous structural alterations underlying

87 the clinical manifestations, including airway disease, emphysema, and vascular

88 abnormalities.[3]

The single-breath lung diffusion capacity for carbon monoxide ( $\left.\mathrm{D}_{\mathrm{LCO}}\right)$ is a

90 noninvasive, repeatable physiological measure of the capacity of gas exchange in the

91 alveolar space of the lungs.[4, 5] $\mathrm{D}_{\text {LCO }}$ is closely associated with emphysema measured

92 on histology[6, 7] and computed tomography (CT)[8], as well as vascular abnormalities

93 on CT.[9, 10, 11] Moreover, a lower $\mathrm{D}_{\mathrm{LCO}}$ is associated with a lower arterial partial

94 pressure of oxygen $\left(\mathrm{PaO}_{2}\right)$, exercise capacity, and poor prognosis in patients with

95 COPD.[12, 13, 14] Even in smokers with normal spirometry, $\mathrm{D}_{\text {LCO }}$ may be decreased, and the decreased $\mathrm{D}_{\mathrm{LCO}}$ is associated with more severe symptoms and impaired exercise

97 capacity[15] and predicts the future development of COPD.[16] Furthermore,

98 Balasubramanian et al.[17] recently proposed the categorization of patients with COPD

99 based on a combination of forced expiratory volume in 1 second (FEV 1 ) on spirometry

100 and $\mathrm{D}_{\mathrm{LCO}}$, and showed that an impaired $\mathrm{D}_{\mathrm{LCO}}(\leq 50 \%$ of predicted) has negative effects on

101 symptoms, exercise capacity, and exacerbation frequency, even in patients without a

102 substantial reduction in $\mathrm{FEV}_{1}$ ( $>50 \%$ of predicted). These findings suggest that functional 103 phenotyping based on $\mathrm{FEV}_{1}$ and $\mathrm{D}_{\mathrm{LCO}}$ may improve clinical COPD management. 
104 However, the detailed structure-function relationships and even long-term prognosis in 105 relation to this phenotyping remain to be explored.

A disproportionally impaired $\mathrm{D}_{\mathrm{LCO}}$ relative to $\mathrm{FEV}_{1}$ was hypothesized to be a

107 common functional phenotype associated with the distinct clinical manifestations,

108 structural changes, and prognosis of COPD. This study aimed to identify patients with

109 COPD presenting a disproportionally impaired $\mathrm{D}_{\mathrm{LCO}}$ relative to $\mathrm{FEV}_{1}$ in two

110 observational cohorts: the Kyoto University Cohort (single-center study in Japan)[8, 18]

111 and the Korea COPD Subgroup Study (KOCOSS) Cohort (multicenter study in

112 Korea).[19, 20] Furthermore, this study tested whether this functional phenotype was

113 associated with impairments in patient-reported outcomes and exercise capacity in the

114 KOCOSS Cohort, and with a greater severity of emphysema on CT, abnormal arterial 115 oxygen and carbon dioxide pressures, and increased long-term mortality in the Kyoto 116 University Cohort.

\section{Methods}

\section{Study design}

120 The present study consisted of the following datasets from two independent cohorts: the

121 cross-sectional data from the KOCOSS Cohort and the cross-sectional and longitudinal

122 data from the Kyoto University Cohort. The KOCOSS Cohort was obtained from a

123 multicenter prospective observational study conducted at 48 tertiary referral hospitals in

124 the Republic of Korea beginning in 2011.[19, 20] The study protocol was approved by

125 the Institutional Review Board of Konkuk University Medical Center (Institutional

126 Review Board No. 177 KHH1010338), and all the hospitals obtained approval from the 
127 Institutional Review Board committee. The Kyoto University Cohort is a single-center 128 prospective observational study that has been conducted at the Kyoto University Hospital 129 in Japan since 2006 using a single CT scanner with the fixed scanning conditions 130 described below.[8, 18, 21] The study was performed in accordance with the Declaration 131 of Helsinki and was approved by the Ethics Committee of Kyoto University (approval 132 Nos. E182 and R1660-1). All participants in both the Kyoto University and KOCOSS 133 cohorts provided written informed consent. The collaborative analysis of the two cohorts 134 was further approved by the Ethics Committee of Kyoto University (approval No. 135 R2033).

136 The inclusion criteria of the present study were as follows: (1) age 40-85 years 137 with a smoking history of at least 10 pack-years, (2) a physician's diagnosis of COPD 138 based on patient-reported respiratory symptoms and the presence of airflow limitation 139 confirmed by a postbronchodilator $\mathrm{FEV}_{1} /$ forced vital capacity (FVC) ratio below the 140 lower limit of normal (LLN), and (3) availability of postbronchodilator spirometry and 141 D LCO. D LCo was adjusted by the blood hemoglobin level according to a previous report. 142 [22] The LLN of FEV 1 /FVC and z-scores and reference values of FEV 1 and FVC were 143 obtained based on the “other” ethnic group data provided by the Global Lung Function 144 Initiative (GLI) 2012. [23] The z-scores and reference values of $\mathrm{D}_{\text {LCO }}$ was also calculated 145 using the GLI calculation system.[4] Patients with a history of lung resection surgery or 146 other lung diseases, such as interstitial lung disease and those with alpha-1 antitrypsin 
147 deficiency, were excluded. Because the majority (>90\%) of patients enrolled in the two 148 cohorts were male, female patients were also excluded.

149 In the KCOSS Cohort, patient-reported outcomes, including the mMRC dyspnea

150 scale, COPD assessment test (CAT), and St. George's Respiratory Questionnaire

151 (SGRQ),[24, 25] and exercise capacity as assessed by the 6-minute walking distance

152 (6MWD) were cross-sectionally evaluated. capacity (TLC) ratio (RV/TLC), mMRC, emphysema and airway diseases on inspiratory

$155 \mathrm{CT}$ and arterial blood gases measured in room air, including $\mathrm{PaO}_{2}$ and partial pressure of 156 carbon dioxide $\left(\mathrm{PaCO}_{2}\right)$ at baseline, were cross-sectionally evaluated. The $\mathrm{CO}$ transfer 157 coefficient $(\mathrm{Kco})$ that corresponds to $\mathrm{D}_{\mathrm{LCO}}$ divided by alveolar volume $\left(\mathrm{V}_{\mathrm{A}}\right)$ was also 158 measured. Furthermore, longitudinal follow-up survival data available as of October 2019 159 from the Kyoto University Cohort were evaluated.

160 Chest CT

161 All subjects in the Kyoto University Cohort underwent full inspiratory CT with a peak 162 kilovoltage of 120, a 0.5-second exposure time, and autoexposure control using an 163 Aquilion 64 scanner (Cannon Medical; Tokyo, Japan). Images with a 0.5-mm slice 164 thickness were reconstructed with a high spatial frequency algorithm (FC56). Using a 165 SYNAPSE VINCENT volume analyzer (FUJIFILM Medical, Tokyo, Japan), the 166 percentage of low attenuation regions less than $-950 \mathrm{HU}$ to the total lung regions 167 (LAV\%) was calculated to evaluate emphysema.[26, 27, 28] The wall area percentage 168 (WA\%), which was defined as the percentage of the wall area relative to the sum of the 169 wall and lumen areas, was measured for the right apical and posterior basal segmental 
170 bronchus and averaged to evaluate airway disease.[29, 30, 31] Mild and substantial

171 paraseptal emphysema (PSE), and mild and substantial (moderate to advanced)

172 centrilobular emphysema (CLE) were visually identified based on the Fleischner Society

173 classification system.[32] The inter-rater variability of two pulmonologists (NT and HS)

174 was excellent (kappa $=0.80$ and 0.76 for the PSE and CLE evaluations). Substantial PSE

175 and CLE were considered to indicate the presence of PSE and CLE in this study. In

176 addition, the ratio of the pulmonary artery diameter to the aorta diameter (PA/Ao) was

177 obtained by manually measuring the pulmonary and aorta diameters.[33]

\section{Statistics}

179 The data are reported as means \pm SD, unless indicated otherwise. Statistical analyses

180 were performed with the R program.[34] A p-value less than 0.05 was considered 181 statistically significant. Based on the z-scores of FEV 1 and $\mathrm{D}_{\mathrm{LCO}}$, [35] the patients were

182 categorized into the following 4 groups: (1) FEV 1 z-score $>-3$ and DLCo z-score $>-3$

183 (reference), (2) $\mathrm{FEV}_{1} \mathrm{z}$-score $>-3$ and $\mathrm{D}_{\mathrm{LCO}} \mathrm{z}$-score $\leq-3$ (disproportionally impaired

$184 \mathrm{D}_{\mathrm{LCO}}$ ), (3) FEV 1 z-score $\leq-3$ and $\mathrm{D}_{\mathrm{LCO}} \mathrm{z}$-score $>-3$ (disproportionally impaired FEV $_{1}$ ),

185 and (4) FEV 1 z-score $\leq-3$ and $D_{\text {LCO }}$ z-score $\leq-3$ (mixed-impaired). Tukey’s method was

186 used to compare the variables among the 4 groups. Multivariable linear regression and

187 Cox proportional hazard models were constructed and adjusted for age, height, weight, 188 and smoking pack-years to examine the effects of the disproportionally impaired $\mathrm{D}_{\mathrm{LCO}}$, 189 disproportionally impaired $\mathrm{FEV}_{1}$, and mixed-impaired groups on the clinical measures 190 and long-term outcome in comparison with the reference group. Furthermore, similar 
191 analyses were performed by defining the 4 groups using a cut-off of $50 \%$ for the $\%$ of 192 predicted FEV 1 and DLCO.

196 Figure 1 shows patient flowcharts for the two cohorts. In the KOCOSS Cohort, 743 male 197 patients whose hemoglobin-adjusted $\mathrm{D}_{\mathrm{LCO}}$ was available and $\mathrm{FEV}_{1} / \mathrm{FVC}$ was below the 198 LNN were included in the cross-sectional analysis. In the Kyoto University Cohort, of the 199253 stable patients with COPD enrolled from January to December 2012, 195 male 200 patients with an $\mathrm{FEV}_{1} / \mathrm{FVC}$ below the LNN were included in the cross-sectional and 201 longitudinal analyses. Table 1 shows the basic clinical data of the two cohorts.

203 were categorized into the reference, disproportionally impaired DLCo, disproportionally

204 impaired $\mathrm{FEV}_{1}$, and mixed-impaired groups in both cohorts, respectively

$205(n=351 / 212 / 62 / 118$ in the KOCOSS Cohort, and $n=89 / 62 / 10 / 34$ in the Kyoto University 206 Cohort).

The cross-sectional analysis of the KOCOSS Cohort showed that age, smoking 208 pack-years, $\mathrm{mMRC} \geq 2$, CAT, and the SGRQ scores were higher while the BMI and 6209 minute walking distance were lower in the disproportionally impaired DLco group, as

210 shown in Table 2. In the multivariable analysis shown in Figure 3, compared to the 211 reference group, the disproportionally impaired $\mathrm{D}_{\text {LCO }}$ was significantly associated with 212 higher mMRC, CAT, and SGRQ scores and a lower 6MWD. 
214 Cohort presented in Table 3 showed that age, an $m M R C \geq 2$, the prevalence of visual CT

215 findings of CLE and PSE, and $\mathrm{LAV} \%$ were higher while the $\mathrm{PaO}_{2}$, and $\mathrm{PaCO}_{2}$ were

216 lower in the disproportionally impaired group than in the reference group. WA\% and

217 PA/Ao on CT did not significantly differ among the groups. In the multivariable analysis

218 shown in Figure 4, the rates of both PSE and CLE were higher and $\mathrm{PaO}_{2}$ and $\mathrm{PaCO}_{2}$ were

219 lower in the disproportionally impaired DLCo group than in the reference group. In

220 contrast, the rates of PSE and $\mathrm{PaCO}_{2}$ in the disproportionally impaired $\mathrm{FEV}_{1}$ and mixed-

221 impaired groups did not significantly differ from those in the reference group.

Of the 195 male patients enrolled in the Kyoto University Cohort from 2006 to

223 2012, 52 had died as of October 2019. As shown in Figure 5A, the survival rate differed

224 among the 4 groups. In Figure 5B, the percentages of respiratory disease-related deaths

225 were 29, 36, 0, and 67\% in the reference, disproportionally impaired DLCo,

226 disproportionally impaired $\mathrm{FEV}_{1}$, and mixed-impaired groups, respectively. In the

227 multivariable Cox proportional hazard model shown in Figure 5C, the disproportionally

228 impaired DLCo and mixed-impaired groups had similar effects on all-cause mortality (HR

$229 \quad[95 \%$ confidence interval (CI)] = 3.09 [1.52-6.29] and 3.53[1.56-8.03], respectively),

230 whereas the effect of the disproportionally impaired $\mathrm{FEV}_{1}$ on all-cause mortality was not

231 significant $(\mathrm{HR}[95 \% \mathrm{CI}]=0.91[0.19-4.19])$. The prognostic effect of the

232 disproportionally impaired $\mathrm{D}_{\text {LCO }}$ was detected even after adjusting for LAV\% (HR [95\%

$233 \mathrm{CI}]=2.55[1.21-5.34])$.

Furthermore, additional analyses were performed using the \% predicted $\mathrm{FEV}_{1}$ and

235 DLCo to categorize patients into the 4 groups (see the online supplemental figures S1 and 
236 S2). While the percentage of subjects with the disproportionally impaired DLco, defined 237 using the z-scores of $\mathrm{FEV}_{1}$ and $\mathrm{D}_{\mathrm{LCO}}$, was 29 and $31 \%$ in the KOCOSS and Kyoto

238 University cohorts, the use of the \% predicted value -based definition of this subtype (\%

239 of predicted $\mathrm{FEV}_{1}>50 \%$ and $\%$ of predicted $\mathrm{D}_{\mathrm{LCO}} \leq 50 \%$ ) changed the percentages to

$24018 \%$ and $21 \%$ in the KOCOSS and Kyoto University cohorts, respectively. Nonetheless,

241 the disproportionally impaired $\mathrm{D}_{\mathrm{LCO}}$ relative to $\mathrm{FEV}_{1}$ based on the \% predicted value was

242 significantly associated with an increase in MRC, CAT, and SGRQ scores in the

243 KOCOSS cohort, and with increased odds ratio of the presence of PSE and CLE, lower

$244 \mathrm{PaO}_{2}$ and $\mathrm{PaCO}_{2}$, and higher mortality in the Kyoto University Cohort.

245

Discussion

247 This study shows that a disproportionally impaired $\mathrm{D}_{\mathrm{LCO}}$ relative to $\mathrm{FEV}_{1}$ was common 248 (approximately 30\%) in patients with COPD in two cohorts from different countries. This 249 functional subgroup presented an increased severity of symptoms, impaired quality of life 250 and exercise capacity, greater PSE and CLE, and lower $\mathrm{PaO}_{2}$ and $\mathrm{PaCO}_{2}$ than the 251 reference group. Furthermore, the longitudinal data collected over 10 years from the 252 Kyoto University Cohort shows that this group exhibited a higher risk of long-term 253 mortality. These findings highlight the clinical relevance of identifying a 254 disproportionally impaired $\mathrm{D}_{\mathrm{LCO}}$ relative to $\mathrm{FEV}_{1}$ in COPD management.

$255 \quad D_{\text {LCO }}$ reflects emphysema more strongly than $\mathrm{FEV}_{1}$ and predicts future 256 emphysema progression and mortality.[12, 36] Nonetheless, FEV ${ }_{1}$ on spirometry has 257 been exclusively used in clinical practice and research fields until Balasubramanian et 258 al.[17] recently showed the utility of categorizing patients with COPD based on a 
259 combination of $\mathrm{FEV}_{1}$ and $\mathrm{D}_{\mathrm{LCO}}$. The present data confirm and extend those previous

260 findings by showing that the disproportionally impaired $\mathrm{D}_{\mathrm{LCO}}$ is associated with worse

261 patient-reported outcomes, an abnormal gas exchange, higher rates of PSE and CLE, and

262 increased mortality rates in patients with COPD. In particular, the finding that the hazard

263 ratio of mortality did not differ between the disproportionally impaired $\mathrm{D}_{\mathrm{LCO}}$ and mixed-

264 impaired groups is important, as it improves our ability to estimate the prognosis of

265 patients with COPD.

The rates of both PSE and CLE were higher in the disproportionally impaired

267 DLCo group, while the rate of CLE, but not PSE, was higher in the disproportionally

268 impaired $\mathrm{FEV}_{1}$ and mixed-impaired groups than in the reference group. This result is

269 consistent with a previous finding that a reduced in $\mathrm{FEV}_{1}$ is associated with CLE, but not

270 PSE.[37, 38, 39] A recent microCT study showed relatively milder small airway disease

271 in PSE than CLE regions in explanted lungs from patients with COPD.[40] Collectively,

272 the disproportionally impaired DLCo might reflect more severe emphysema, particularly

273 PSE, with relatively less damage to the airways in patients with COPD.

274 The disproportionally impaired $D_{\text {LCo }}$ group showed a higher mortality than the

275 reference group, even after adjusting for LAV\%. An impaired diffusion capacity is

276 associated with emphysema, pulmonary vascular abnormalities,[6, 9, 10, 11] and

277 dysfunction of pulmonary microvascular perfusion,[41] even in patients with mild

278 COPD. Therefore, the disproportionally impaired DLCo might reflect pulmonary vascular

279 dysfunction and might be associated with increased mortality independent of the

280 emphysema severity. 
The present data showing associations between the disproportionally impaired

$282 \mathrm{D}_{\mathrm{LCO}}$ and lower $\mathrm{PaO}_{2}$ and $\mathrm{PaCO}_{2}$, confirms a previous finding that the diffusion capacity is correlated with $\mathrm{PaO}_{2}$.[12] Additionally, the data are the first to show that a lower $\mathrm{D}_{\mathrm{LCO}}$

284 is associated with a lower $\mathrm{PaCO}_{2}$ in patients with a relatively preserved $\mathrm{FEV}_{1}$. This result 285 is also consistent with a previous finding that differences in alveolar-arterial oxygen

286 levels characterized by decreases in both $\mathrm{PaCO}_{2}$ and $\mathrm{PaO}_{2}$ precede chronic respiratory 287 failure in patients with COPD.[13] Therefore, $\mathrm{PaCO}_{2}$ may be decreased in the early stage 288 of emphysema development and $\mathrm{D}_{\mathrm{LCO}}$ impairment, and then become increased in the late 289 stage of the disease to eventually cause chronic hypercapnic respiratory failure. The use of two cohorts from Japan and Korea is an advantage of this study. The 291 two cohorts consistently showed similar frequencies in the 4 groups, suggesting that the 292 disproportionally impaired $\mathrm{D}_{\mathrm{LCO}}$ relative to $\mathrm{FEV}_{1}$ is commonly identified in patients with 293 COPD. Interestingly, the percentage of this functional phenotype was higher than the 294 value documented in a previous report from the COPDGene study.[17] The discrepancy 295 might be due to the different severity between the studies as \% of predicted $\mathrm{FEV}_{1}$ in the 296 previous study (70\%) was higher than in the present two cohorts. $\mathrm{FEV}_{1} / \mathrm{FVC}$ decreases with age and may cause an overdiagnosis of COPD in 298 elderly subjects.[35, 42, 43] Therefore, the present study defined the airflow limitation 299 based on $\mathrm{FEV}_{1} / \mathrm{FVC}<\mathrm{LNN}$, but not $\mathrm{FEV}_{1} / \mathrm{FVC}<0.7$ (the Global Initiative for Chronic 300 Obstructive Lung Disease [GOLD] criteria[2]). Indeed, as shown in Supplemental Figure 301 S3, of 798 males with $\mathrm{FEV}_{1} / \mathrm{FVC}<0.7$ in the KOCOSS cohort, 55 males showed 302 FEV1/FVC $\geq \mathrm{LLN}$, and age was higher in those with $\mathrm{FEV}_{1} / \mathrm{FVC} \geq \mathrm{LNN}$ than those with $303 \mathrm{FEV}_{1} / \mathrm{FVC}<\mathrm{LLN}$. 
This study has some limitations. First, although cardiac dysfunction and

305 pulmonary hypertension may affect $D_{\text {LCo, }}$ the present study did not examine the possible

306 effects of these abnormalities using echocardiography and heart catheterization.

307 However, PA/Ao, which is a good marker for pulmonary hypertension,[44] did not differ

308 significantly between the four groups in this study. Second, the present study analyzed

309 the data from male patients. Further studies are needed to confirm whether the findings

310 from the present study are generalizable to female subjects.

\section{Conclusion}

313 In the present study, the data obtained from the Korean and Japanese cohorts show that a

314 disproportionally impaired $\mathrm{D}_{\mathrm{LCO}}$ relative to $\mathrm{FEV}_{1}$ is a common functional phenotype in

315 patients with COPD. The identification of this phenotype may improve our understanding

316 of the various clinical manifestations of each individual and help non-invasively estimate

317 the long-term prognosis of patients with COPD in daily practice. 


\section{References}

320 1. Adeloye D, Chua S, Lee C, et al. Global and regional estimates of COPD 321 prevalence: Systematic review and meta-analysis. J Glob Health. 2015 Dec;5(2):020415. doi: 10.7189/jogh.05-020415. PubMed PMID: 26755942; PubMed Central PMCID: PMCPMC4693508.

2. Vogelmeier CF, Criner GJ, Martinez FJ, et al. Global Strategy for the Diagnosis, Management, and Prevention of Chronic Obstructive Lung Disease 2017 Report: GOLD Executive Summary. Eur Respir J. 2017 Mar;49(3). doi: 10.1183/13993003.00214-2017. PubMed PMID: 28182564.

3. Hogg JC. Pathophysiology of airflow limitation in chronic obstructive pulmonary disease. Lancet. 2004 Aug 21-27;364(9435):709-21. doi: 10.1016/S01406736(04)16900-6. PubMed PMID: 15325838.

4. Stanojevic S, Graham BL, Cooper BG, et al. Official ERS technical standards: Global Lung Function Initiative reference values for the carbon monoxide transfer factor for Caucasians. Eur Respir J. 2017 Sep;50(3). doi: 10.1183/13993003.000102017. PubMed PMID: 28893868.

5. Radovanovic D, Contoli M, Marco FD, et al. Clinical and Functional Characteristics of COPD Patients Across GOLD Classifications: Results of a Multicenter Observational Study. COPD. 2019 Aug;16(3-4):215-226. doi: 10.1080/15412555.2019.1659760. PubMed PMID: 31500459.

6. Gould GA, MacNee W, McLean A, et al. CT measurements of lung density in life can quantitate distal airspace enlargement--an essential defining feature of human emphysema. Am Rev Respir Dis. 1988 Feb;137(2):380-92. doi: 
10.1164/ajrccm/137.2.380. PubMed PMID: 3341629.

$343 \quad 7 . \quad$ Morrison NJ, Abboud RT, Muller NL, et al. Pulmonary capillary blood volume in emphysema. Am Rev Respir Dis. 1990 Jan;141(1):53-61. doi: 10.1164/ajrccm/141.1.53. PubMed PMID: 2297187.

8. Tanabe N, Muro S, Hirai $\mathrm{T}$, et al. Impact of exacerbations on emphysema progression in chronic obstructive pulmonary disease. Am J Respir Crit Care Med.

9. Cho YH, Lee SM, Seo JB, et al. Quantitative assessment of pulmonary vascular 351

11. Matsuoka S, Washko GR, Yamashiro T, et al. Pulmonary hypertension and computed tomography measurement of small pulmonary vessels in severe emphysema. Am J Respir Crit Care Med. 2010 Feb 1;181(3):218-25. doi: 10.1164/rccm.200908-1189OC. PubMed PMID: 19875683; PubMed Central PMCID: PMCPMC2817812.

12. Boutou AK, Shrikrishna D, Tanner RJ, et al. Lung function indices for predicting mortality in COPD. Eur Respir J. 2013 Sep;42(3):616-25. doi: 

PMCID: PMCPMC3759303.

13. Uemasu K, Sato S, Muro S, et al. Annual decline in arterial blood oxygen predicts 368 development of chronic respiratory failure in COPD with mild hypoxaemia: A 6year follow-up study. Respirology. 2019 Mar;24(3):262-269. doi:

371 14. Santus P, Radovanovic D, Balzano G, et al. Improvements in Lung Diffusion Capacity following Pulmonary Rehabilitation in COPD with and without Ventilation Inhomogeneity. Respiration. 2016;92(5):295-307. doi: 10.1159/000448847. PubMed PMID: 27598467.

375 15. Kirby M, Owrangi A, Svenningsen S, et al. On the role of abnormal DL(CO) in ex376 smokers without airflow limitation: symptoms, exercise capacity and hyperpolarised helium-3 MRI. Thorax. 2013 Aug;68(8):752-9. doi: 10.1136/thoraxjnl-2012-203108. PubMed PMID: 23604381.

16. Harvey BG, Strulovici-Barel Y, Kaner RJ, et al. Risk of COPD with obstruction in active smokers with normal spirometry and reduced diffusion capacity. Eur Respir J. 2015 Dec;46(6):1589-1597. doi: 10.1183/13993003.02377-2014. PubMed PMID: 26541521; PubMed Central PMCID: PMCPMC4752006.

383 17. Balasubramanian A, MacIntyre NR, Henderson RJ, et al. Diffusing Capacity of Carbon Monoxide in Assessment of COPD. Chest. 2019 Dec;156(6):1111-1119. 385 doi: 10.1016/j.chest.2019.06.035. PubMed PMID: 31352035.

18. Tanimura K, Sato S, Fuseya Y, et al. Quantitative Assessment of Erector Spinae 387 Muscles in Patients with Chronic Obstructive Pulmonary Disease. Novel Chest 
Computed Tomography-derived Index for Prognosis. Ann Am Thorac Soc. 2016

389

Mar;13(3):334-41. doi: 10.1513/AnnalsATS.201507-446OC. PubMed PMID:

390

26700501.

391 19. Lee JY, Chon GR, Rhee CK, et al. Characteristics of Patients with Chronic

Obstructive Pulmonary Disease at the First Visit to a Pulmonary Medical Center in

Korea: The KOrea COpd Subgroup Study Team Cohort. J Korean Med Sci. 2016

394

Apr;31(4):553-60. doi: 10.3346/jkms.2016.31.4.553. PubMed PMID: 27051239;

PubMed Central PMCID: PMCPMC4810338.

20. Rhee CK, Kim JW, Hwang YI, et al. Discrepancies between modified Medical

Research Council dyspnea score and COPD assessment test score in patients with

COPD. Int J Chron Obstruct Pulmon Dis. 2015;10:1623-31. doi:

10.2147/COPD.S87147. PubMed PMID: 26316736; PubMed Central PMCID:

401 21. Tanabe N, Sato S, Tanimura K, et al. Associations of CT evaluations of antigravity muscles, emphysema and airway disease with longitudinal outcomes in patients with COPD. Thorax. 2020 2020-08-31 00:00:00.

404

22. Macintyre N, Crapo RO, Viegi G, et al. Standardisation of the single-breath 405 determination of carbon monoxide uptake in the lung. Eur Respir J. 2005 Oct;26(4):720-35. doi: 10.1183/09031936.05.00034905. PubMed PMID:

408 23. Quanjer PH, Stanojevic S, Cole TJ, et al. Multi-ethnic reference values for 409 spirometry for the 3-95-yr age range: the global lung function 2012 equations.

European Respiratory Journal. 2012;40(6):1324-1343. doi: 
412 24. Jones PW, Quirk FH, Baveystock CM, et al. A self-complete measure of health status for chronic airflow limitation. The St. George's Respiratory Questionnaire. Am Rev Respir Dis. 1992 Jun;145(6):1321-7. doi: 10.1164/ajrccm/145.6.1321. PubMed PMID: 1595997.

416 25. Choi JY, Yoon HK, Shin KC, et al. CAT Score and SGRQ Definitions of Chronic 417 Bronchitis as an Alternative to the Classical Definition. Int J Chron Obstruct Pulmon Dis. 2019;14:3043-3052. doi: 10.2147/COPD.S228307. PubMed PMID: 31920301; PubMed Central PMCID: PMCPMC6941605.

26. Gevenois PA, De Vuyst P, de Maertelaer V, et al. Comparison of computed density 421 and microscopic morphometry in pulmonary emphysema. Am J Respir Crit Care 422 Med. 1996 Jul;154(1):187-92. doi: 10.1164/ajrccm.154.1.8680679. PubMed PMID: 8680679.

424 27. Shimizu K, Tanabe N, Tho NV, et al. Per cent low attenuation volume and fractal dimension of low attenuation clusters on CT predict different long-term outcomes in COPD. Thorax. 2020 Feb;75(2):116-122. doi: 10.1136/thoraxjnl-2019-213525. PubMed PMID: 31896733.

428 28. Shima H, Tanabe N, Sato S, et al. Lobar distribution of non-emphysematous gas 429 trapping and lung hyperinflation in chronic obstructive pulmonary disease. Respir Investig. 2020 Jul;58(4):246-254. doi: 10.1016/j.resinv.2020.01.001. PubMed

432 29. Oguma T, Hirai T, Niimi A, et al. Limitations of airway dimension measurement on 433 images obtained using multi-detector row computed tomography. PLoS One. 
2013;8(10):e76381. doi: 10.1371/journal.pone.0076381. PubMed PMID: 24116105; PubMed Central PMCID: PMCPMC3792973.

30. Nakano Y, Muro S, Sakai H, et al. Computed tomographic measurements of airway dimensions and emphysema in smokers. Correlation with lung function. Am J Respir Crit Care Med. 2000 Sep;162(3 Pt 1):1102-8. doi: 10.1164/ajrccm.162.3.9907120. PubMed PMID: 10988137.

31. Tanabe N, Oguma T, Sato S, et al. Quantitative measurement of airway dimensions using ultra-high resolution computed tomography. Respir Investig. 2018 Nov;56(6):489-496. doi: 10.1016/j.resinv.2018.07.008. PubMed PMID: 30392536.

32. Lynch DA, Austin JH, Hogg JC, et al. CT-Definable Subtypes of Chronic Obstructive Pulmonary Disease: A Statement of the Fleischner Society. Radiology. 2015 Oct;277(1):192-205. doi: 10.1148/radiol.2015141579. PubMed PMID: 25961632; PubMed Central PMCID: PMCPMC4613878.

33. Wells JM, Washko GR, Han MK, et al. Pulmonary arterial enlargement and acute exacerbations of COPD. N Engl J Med. 2012 Sep 6;367(10):913-21. doi: 10.1056/NEJMoa1203830. PubMed PMID: 22938715; PubMed Central PMCID: PMCРMC3690810.

34. R Core Team. R: A Language and Environment for Statistical Computing. URL http://www.R-project.org/. 2015.

35. Quanjer PH, Pretto JJ, Brazzale DJ, et al. Grading the severity of airways obstruction: new wine in new bottles. Eur Respir J. 2014 Feb;43(2):505-12. doi: 10.1183/09031936.00086313. PubMed PMID: 23988764.

36. Mohamed Hoesein FA, Zanen P, van Ginneken B, et al. Association of the transfer 
coefficient of the lung for carbon monoxide with emphysema progression in male smokers. Eur Respir J. 2011 Nov;38(5):1012-8. doi: 10.1183/09031936.00050711. PubMed PMID: 21565924.

37. Smith BM, Austin JH, Newell JD, Jr., et al. Pulmonary emphysema subtypes on computed tomography: the MESA COPD study. Am J Med. 2014 Jan;127(1):94 e723. doi: 10.1016/j.amjmed.2013.09.020. PubMed PMID: 24384106; PubMed Central PMCID: PMC3882898.

38. Araki T, Nishino M, Zazueta OE, et al. Paraseptal emphysema: Prevalence and distribution on CT and association with interstitial lung abnormalities. Eur J Radiol. 2015 Jul;84(7):1413-8. doi: 10.1016/j.ejrad.2015.03.010. PubMed PMID: 25868675; PubMed Central PMCID: PMCPMC4450117.

39. Park J, Hobbs BD, Crapo JD, et al. Subtyping COPD by Using Visual and Quantitative CT Imaging Features. Chest. 2020 Jan;157(1):47-60. doi: 10.1016/j.chest.2019.06.015. PubMed PMID: 31283919; PubMed Central PMCID: PMCPMC6965698.

40. Tanabe N, Vasilescu DM, Hague CJ, et al. Pathological Comparisons of Paraseptal and Centrilobular Emphysema in Chronic Obstructive Pulmonary Disease. Am J Respir Crit Care Med. 2020 Sep 15;202(6):803-811. doi: 10.1164/rccm.2019122327OC. PubMed PMID: 32485111.

41. Hueper K, Vogel-Claussen J, Parikh MA, et al. Pulmonary Microvascular Blood Flow in Mild Chronic Obstructive Pulmonary Disease and Emphysema. The MESA COPD Study. Am J Respir Crit Care Med. 2015 Sep 1;192(5):570-80. doi: 10.1164/rccm.201411-21200C. PubMed PMID: 26067761; PubMed Central 
PMCID: PMCPMC4595687.

481 42. Quanjer PH, Brazzale DJ, Boros PW, et al. Implications of adopting the Global Lungs Initiative 2012 all-age reference equations for spirometry. Eur Respir J. 2013 Oct;42(4):1046-54. doi: 10.1183/09031936.00195512. PubMed PMID: 23520323.

43. Kubota M, Kobayashi H, Quanjer PH, et al. Reference values for spirometry, including vital capacity, in Japanese adults calculated with the LMS method and 486 compared with previous values. Respir Investig. 2014 Jul;52(4):242-50. doi: 10.1016/j.resinv.2014.03.003. PubMed PMID: 24998371.

44. Devaraj A, Wells AU, Meister MG, et al. Detection of pulmonary hypertension with multidetector CT and echocardiography alone and in combination. Radiology. 2010 
493 Tables

494 Table 1. Demographics of patients in the two cohorts

\begin{tabular}{|c|c|c|}
\hline & KOCOSS & Kyoto University \\
\hline $\mathrm{N}$ & 743 & 195 \\
\hline Age (years) & $68.9(7.6)$ & $69.9(8.5)$ \\
\hline Male (\%) & $100 \%$ & $100 \%$ \\
\hline Smoking pack-years & $47.2(24.2)$ & $67.2(34.7)$ \\
\hline Height (cm) & $165.4(5.6)$ & $164.5(6.1)$ \\
\hline Weight (kg) & $62.8(9.6)$ & 59.8 (9.3) \\
\hline Body mass index & $22.9(3.1)$ & 22.1 (2.9) \\
\hline $\mathrm{FEV}_{1}$ (\% predicted) & $62.4(19.2)$ & $61.6(19.7)$ \\
\hline FVC (\% predicted) & $101.9(19.2)$ & $101.0(18.4)$ \\
\hline $\mathrm{FEV}_{1}$ (z-score) & $-2.2(1.1)$ & $-2.2(1.1)$ \\
\hline FVC (z-score) & $0.1(1.3)$ & $0.0(1.3)$ \\
\hline $\mathrm{FEV}_{1} / \mathrm{FVC}$ & $0.48(0.11)$ & $0.48(0.12)$ \\
\hline DLCO (\% predicted) & $58.1(19.1)$ & $58.0(21.9)$ \\
\hline DLCO (z-score) & $-3.0(1.6)$ & $-3.0(1.9)$ \\
\hline $\mathrm{mMRC} \geq 2(\%)$ & $34 \%$ & $25 \%$ \\
\hline
\end{tabular}


Table 2. Clinical characteristics of the $\mathbf{4}$ groups in the KOCOSS Cohort

\begin{tabular}{|c|c|c|c|c|c|}
\hline & Reference & $\begin{array}{c}\text { Disproportion } \\
\text { ally impaired } \\
\text { DLCO }\end{array}$ & $\begin{array}{c}\text { Disproportion } \\
\text { ally impaired } \\
\mathrm{FEV}_{1}\end{array}$ & $\begin{array}{l}\text { Mixed- } \\
\text { impaired }\end{array}$ & $\mathrm{P}$ \\
\hline $\mathrm{N}$ & 351 & 212 & 62 & 118 & \\
\hline Age (years) & $69.0(7.6)$ & $70.4(7.6)$ & $65.7(7.1)^{\dagger}$ & $67.6(7.3)$ & $<0.01$ \\
\hline Smoking PY & $44.2(22.7)$ & $51.3(25.6)^{\dagger}$ & $45.3(20.2)$ & $49.4(26.9)$ & $<0.01$ \\
\hline BMI & $23.9(2.8)$ & $22.1(3.0)^{\dagger}$ & $23.3(3.1)$ & $21.2(3.0)^{\dagger}$ & $<0.01$ \\
\hline $\mathrm{FEV}_{1}$ (z-score) & $-1.7(0.8)$ & $-1.9(1.2)^{\dagger}$ & $-3.4(0.4)^{\dagger}$ & $-3.6(0.4)^{\dagger}$ & $<0.01$ \\
\hline FVC (z-score) & $0.4(1.1)$ & $0.5(1.1)$ & $-1.0(1.2)^{\dagger}$ & $-0.9(1.2)^{\dagger}$ & $<0.01$ \\
\hline DLCo (z-score) & $-1.8(0.8)$ & $-4.3(1.2)^{\dagger}$ & $-2.2(0.7)^{\dagger}$ & $-4.7(1.2)^{\dagger}$ & $<0.01$ \\
\hline $\mathrm{mMRC} \geq 2(\%)$ & $21 \%$ & $34 \%^{\dagger}$ & $55 \%{ }^{\dagger}$ & $59 \%{ }^{\dagger}$ & $<0.01$ \\
\hline 6MWD* (m) & 431 (93) & $404(106)^{\dagger}$ & $417(77)$ & $361(108)^{\dagger}$ & $<0.01$ \\
\hline CAT $^{*}$ & $12.9(7.2)$ & $15.6(8.4)^{\dagger}$ & $17.8(7.4)^{\dagger}$ & $19.6(8.1)^{\dagger}$ & $<0.01$ \\
\hline SGRQ total* & $27.2(17.0)$ & $40.4(18.5)^{\dagger}$ & $39.4(18.5)^{\dagger}$ & $44.6(20.1)^{\dagger}$ & $<0.01$ \\
\hline Symptom* & $35.9(18.1)$ & $48.3(20.1)^{\dagger}$ & $51.6(19.9)^{\dagger}$ & $49.7(20.8)^{\dagger}$ & $<0.01$ \\
\hline Activity* & 38.3(21.9) & $52.9(21.3)^{\dagger}$ & $52.1(22.3)^{\dagger}$ & $59.3(23.5)^{\dagger}$ & $<0.01$ \\
\hline Impact* & $18.4(17.7)$ & $30.9(20.9)^{\dagger}$ & $28.3(19.8)^{\dagger}$ & $34.5(22.1)^{\dagger}$ & $<0.01$ \\
\hline
\end{tabular}

499 years. $\mathrm{BMI}=$ body mass index. $\mathrm{FEV}_{1}=$ forced expiratory volume in 1 second. $\mathrm{FVC}=$ 500 forced vital capacity. RV/TLC = ratio of residual volume to total lung capacity. $\mathrm{D}_{\mathrm{LCO}}=$ 501 diffusion capacity for carbon monoxide. 6MWD = six-minute walking distance. $\mathrm{CAT}=$ 502 COPD assessment test. SGRQ = St. George's Respiratory Questionnaire. Symptom, 503 Activity, and Impact were the domains of the SGRQ score. * 6MWD, CAT, and SGRQ 504 data were available for 641,717 , and 395 patients, respectively. $\mathrm{P}=\mathrm{p}$-value. ${ }^{\dagger} \mathrm{p}<0.05$ 505 compared to the reference group based on Tukey’s multiple comparison or multiple 506 Fisher’s exact tests followed by Bonferroni correction. 
508 Table 3. Clinical characteristics of the 4 groups in the Kyoto University Cohort

\begin{tabular}{|c|c|c|c|c|c|}
\hline & Reference & $\begin{array}{c}\text { Disproportion } \\
\text { ally impaired } \\
\text { DLCO }\end{array}$ & $\begin{array}{c}\text { Disproportion } \\
\text { ally impaired } \\
\text { FEV }_{1}\end{array}$ & $\begin{array}{l}\text { Mixed- } \\
\text { impaired }\end{array}$ & $\mathrm{P}$ \\
\hline $\mathrm{N}$ & 89 & 62 & 10 & 34 & \\
\hline Age (years) & $68.8(9.0)$ & $73.6(6.4)^{\dagger}$ & $67.5(5.1)$ & $66.9(9.2)$ & $<0.01$ \\
\hline Smoking PY & $65.2(34.8)$ & $72.6(35.9)$ & $70.4(39.4)$ & $61.7(30.5)$ & 0.43 \\
\hline BMI & $23.0(2.7)$ & $21.6(3.1)^{\dagger}$ & $21.3(2.4)$ & $20.8(2.7)^{\dagger}$ & $<0.01$ \\
\hline $\mathrm{FEV}_{1}$ (z-score) & $-1.6(0.9)$ & $-2.0(0.8)^{\dagger}$ & $-3.5(0.4)^{\dagger}$ & $-3.7(0.6)^{\dagger}$ & $<0.01$ \\
\hline FVC (z-score) & $0.3(1.1)$ & $0.4(1.0)$ & $-0.7(1.4)^{\dagger}$ & $-1.2(1.2)^{\dagger}$ & $<0.01$ \\
\hline RV/TLC (\%) & $39.2(6.4)$ & $42.3(7.9)^{\dagger}$ & $48.0(11.2)^{\dagger}$ & $48.8(6.1)^{\dagger}$ & $<0.01$ \\
\hline DLCO (z-score) & $-1.6(0.9)$ & $-4.2(1.0)^{\dagger}$ & $-1.7(0.9)$ & $-5.1(1.5)^{\dagger}$ & $<0.01$ \\
\hline Kco (z-score) & $-1.0(1.2)$ & $-3.5(1.0)^{\dagger}$ & $-1.1(0.9)$ & $-4.0(1.5)^{\dagger}$ & $<0.01$ \\
\hline $\mathrm{V}_{\mathrm{A}} / \mathrm{TLC}(\%)$ & $81.8(5.2)$ & $78.4(7.1)^{\dagger}$ & $82.7(7.4)$ & $74.0(7.4)^{\dagger}$ & $<0.01$ \\
\hline $\mathrm{mMRC} \geq 2(\%)$ & $15 \%$ & $32 \%^{\dagger}$ & $10 \%$ & $47 \%^{\dagger}$ & $<0.01$ \\
\hline $\mathrm{PaO}_{2} *(\mathrm{mmHg})$ & 79.6() & $74.0(8.1)^{\dagger}$ & $72.3(9.2)$ & $74.6(7.3)^{\dagger}$ & $<0.01$ \\
\hline $\mathrm{PaCO}_{2} *$ (mmHg) & $39.8(3.5)$ & $38.0(3.7)^{\dagger}$ & $42.4(2.7)$ & $40.2(4.4)$ & $<0.01$ \\
\hline LAV\% (\%) & $24.0(6.8)$ & $32.4(6.9)^{\dagger}$ & $31.4(6.7)^{\dagger}$ & $39.5(8.2)^{\dagger}$ & $<0.01$ \\
\hline WA\% (\%) & $59.7(5.8)$ & $60.3(6.1)$ & $61.3(5.1)$ & $59.1(5.9)$ & 0.68 \\
\hline PSE & $35 \%$ & $58 \%^{\dagger}$ & $10 \%$ & $53 \%$ & $<0.01$ \\
\hline CLE & $29 \%$ & $92 \%^{\dagger}$ & $60 \%$ & $94 \%^{\dagger}$ & $<0.01$ \\
\hline PA/Ao & $0.77(0.11)$ & $0.76(0.10)$ & $0.77(0.06)$ & $0.80(0.13)$ & 0.51 \\
\hline
\end{tabular}

509 Data are presented as means (SD). All subjects were male. Smoking PY = smoking pack-

510 years. $\mathrm{BMI}=$ body mass index. $\mathrm{FEV}_{1}=$ forced expiratory volume in 1 second. $\mathrm{FVC}=$

511 forced vital capacity. RV/TLC = ratio of residual volume to total lung capacity. DLCO $_{\text {L }}$

512 diffusion capacity for carbon monoxide $(\mathrm{CO}) . \mathrm{Kco}=\mathrm{CO}$ transfer coefficient. $\mathrm{VA} / \mathrm{TLC}=$

513 ratio of alveolar volume to total lung capacity. $\mathrm{PaO}_{2}=$ partial pressure of oxygen. $\mathrm{PaCO}_{2}$

$514=$ partial pressure of carbon dioxide. PSE $=$ paraseptal emphysema. CLE $=$ moderate to 
515 severe centrilobular emphysema. LAV\% = low attenuation volume percentage. $\mathrm{WA} \%=$

516 wall area percentage. $\mathrm{PA} / \mathrm{Ao}=$ diameter ratio of pulmonary artery to aorta. ${ }^{*} \mathrm{PaO}_{2}$ and

$517 \mathrm{PaCO}_{2}$ data were available for 184 patients. $\mathrm{P}=$ p-value. ${ }^{\dagger} \mathrm{p}<0.05$ compared to the

518 reference group based on Tukey’s multiple comparison or multiple Fisher's exact tests

519 followed by Bonferroni correction.

520 
$521 \quad$ Figure Legends

522 Figure 1. Patient flow charts

523 A. The KOCOSS Cohort was cross-sectionally analyzed. B. The Kyoto University

524 Cohort was cross-sectionally and longitudinally analyzed.

525

526 Figure 2. Distributions of FEV 1 and $D_{\text {LCO }}$ in the two cohorts

527 A. KOCOSS Cohort. B. Kyoto University Cohort. Patients were categorized into 4

528 groups: (1) FEV 1 z-score $>-3$ and $D_{\text {LCo }}$ z-score $>-3$ (reference, red), (2) FEV 1 z-score $>$

$529-3$ and $D_{\text {LCO Z }}$-score $\leq-3$ (disproportionally impaired $D_{\text {LCO, }}$ green), (3) FEV 1 z-score $\leq-3$

530 and $D_{\text {LCo }}$ z-score $>-3$ (disproportionally impaired $\mathrm{FEV}_{1}$, blue), and (4) FEV $\mathrm{F}_{1} \mathrm{z}$-score $\leq-3$

531 and $\mathrm{D}_{\text {Lco }} \mathrm{z}$-score $\leq-3$ (mixed-impaired, purple).

532

533 Figure 3. Associations of $D_{L C O}, F_{1}$, and both impairments with patient-reported 534 outcomes and exercise capacity in a multivariable analysis of the KOCOSS cohort

535 Patients (n=743) were categorized into 4 groups: (1) FEV 1 z-score $>-3$ and $\mathrm{D}_{\text {LCO }} \mathrm{z}$-score

$536>-3$ (reference, $\mathrm{n}=351$ ), (2) $\mathrm{FEV}_{1}$ z-score $>-3$ and DLCO $_{\text {z-score }} \leq-3$ (disproportionally

537 impaired $\mathrm{D}_{\mathrm{LCO}}, \mathrm{n}=212$ ), (3) FEV 1 z-score $\leq-3$ and $\mathrm{D}_{\mathrm{LCO}} \mathrm{z}$-score $>-3$ (disproportionally

538 impaired $\mathrm{FEV}_{1}, \mathrm{n}=62$ ), and (4) $\mathrm{FEV}_{1}$ z-score $\leq-3$ and $\mathrm{D}_{\text {LCO }}$ z-score $\leq-3$ (mixed-

539 impaired, $\mathrm{n}=118$ ). A dot with an error bar indicates the least square mean (LS mean) with

540 the $95 \%$ CI. * $\mathrm{p}<0.05$ compared to the reference group in the multivariable models. Each

541 model was adjusted for age, pack-years of smoking, height and weight. 6MWD = six-

542 minute walking distance. $\mathrm{CAT}=\mathrm{COPD}$ assessment test. SGRQ $=$ St. George's 
543 Respiratory Questionnaire. *6MWD, CAT, and SGRQ data were available for 641, 717, 544 and 395 patients, respectively.

Figure 4. Associations of DLCo, FEV1, and both impairments with emphysema subtypes and arterial blood gases in a multivariable analysis of the Kyoto University

548 Cohort

549 Patients (n=195) were categorized into 4 groups: (1) FEV 1 Z-score $>-3$ and $\mathrm{D}_{\text {LCO }} \mathrm{Z}$-score $550>-3$ (reference, $\mathrm{n}=89$ ), (2) FEV 1 z-score $>-3$ and DLCo z-score $\leq-3$ (disproportionally 551 impaired DLCo, n=62), (3) FEV 1 z-score $\leq-3$ and $D_{\text {LCO }}$-score $>-3$ (disproportionally 552 impaired $\mathrm{FEV}_{1}, \mathrm{n}=10$ ), and (4) $\mathrm{FEV}_{1}$ z-score $\leq-3$ and DLCO z-score $\leq-3$ (mixed553 impaired, n=34). (A) Odds ratio for the presence of paraseptal emphysema and 554 centrilobular emphysema on CT. A dot with an error bar indicates the regression 555 coefficient with the 95\% CI. (B) Least square mean (LS mean) with the 95\% CI for the 556 partial pressure of oxygen $\left(\mathrm{PaO}_{2}\right)$ and partial pressure of carbon dioxide $\left(\mathrm{PaCO}_{2}\right)$. * $557 \mathrm{p}<0.05$ compared to the reference group in the multivariable models. Each model was 558 adjusted for age, pack-years of smoking, height and weight. $\mathrm{PaO}_{2}$ and $\mathrm{PaCO}_{2}$ data were 559 available for 184 patients.

561 Figure 5. Long-term survival of patients with COPD in the Kyoto University Cohort 562 (A) Kaplan-Meier curves of survival for the 4 groups: (1) FEV 1 Z-score > -3 and DLCo Z563 score $>-3$ (reference, $n=89$ ), (2) FEV 1 z-score $>-3$ and DLCo z-score $\leq-3$

564 (disproportionally impaired $D_{\text {LCO, }}$ =62), (3) $\mathrm{FEV}_{1}$ z-score $\leq-3$ and $\mathrm{D}_{\text {LCO Z-score }}>-3$ 565 (disproportionally impaired $\mathrm{FEV}_{1}, \mathrm{n}=10$ ), and (4) $\mathrm{FEV}_{1} \mathrm{z}$-score $\leq-3$ and $\mathrm{D}_{\mathrm{LCO}} \mathrm{z}$-score $\leq$ - 
5663 (mixed-impaired, n=34). (B) Causes of death. (C) Multivariable Cox proportional

567 hazard models. A dot with an error bar indicates the hazard ratio with $95 \%$ CI. * $\mathrm{p}<0.05$

568 compared to the reference group in the multivariable models. The model used for the

569 upper panel included the group, age, pack-years of smoking, height, and weight as

570 independent variables, and the model used for the lower panel included the group, age,

571 pack-years of smoking, height, weight, and LAV\% (a CT index of emphysema severity)

572 as independent variables. 


\section{Figure 1}

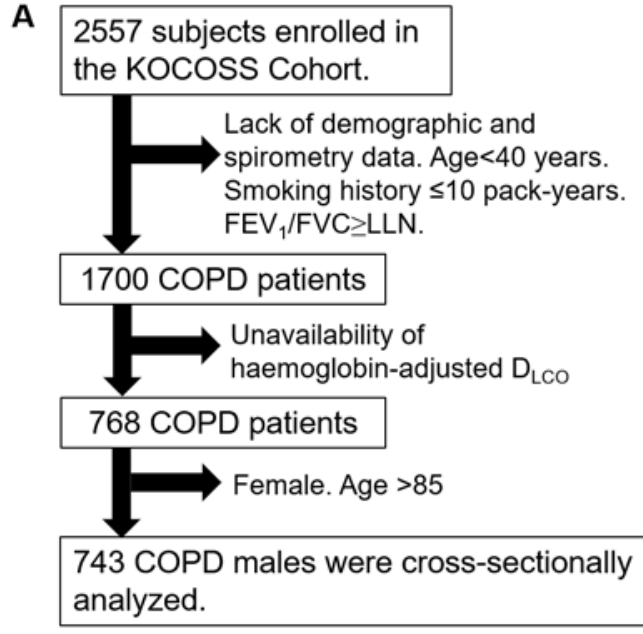

B

253 stable patients with COPD were enrolled in the Kyoto University Cohort from January 2006 to December 2012.

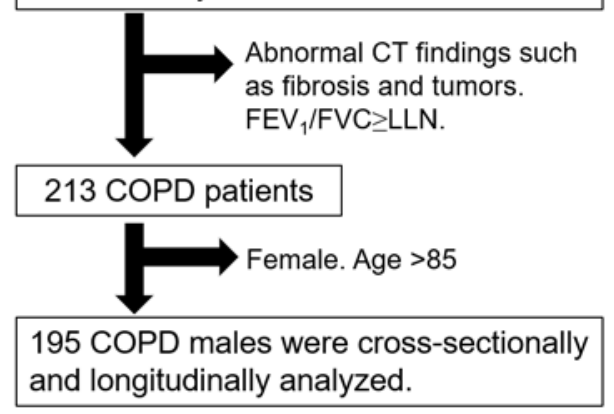


Figure 2

A

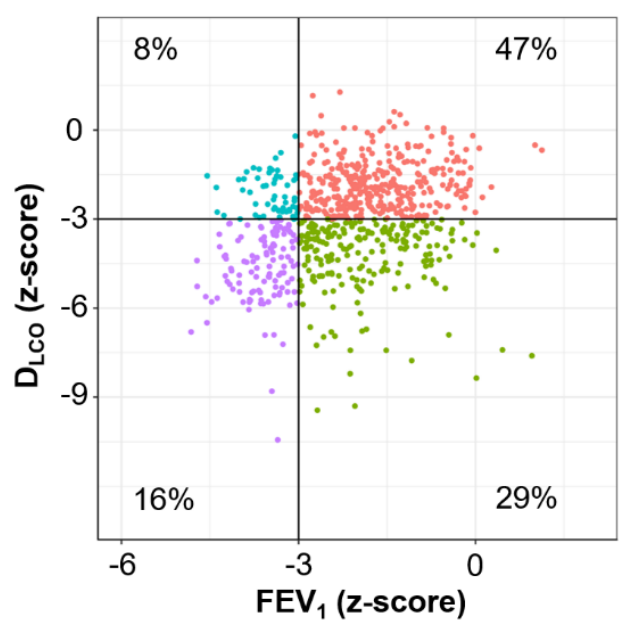

B

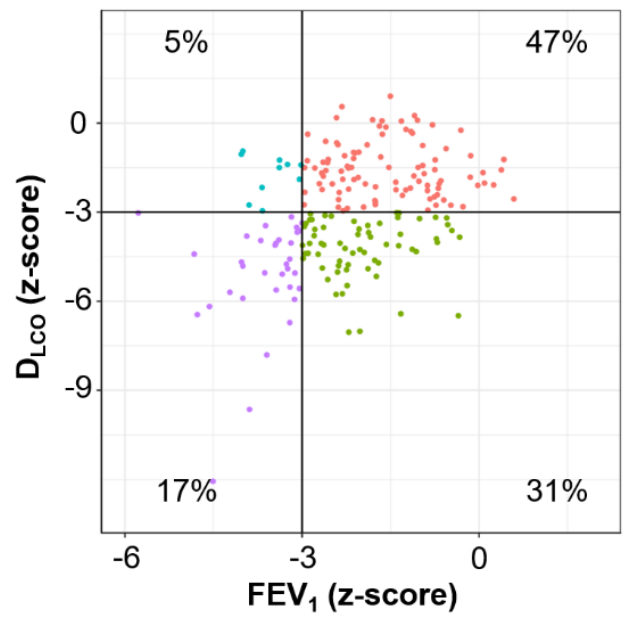




\section{Figure 3}

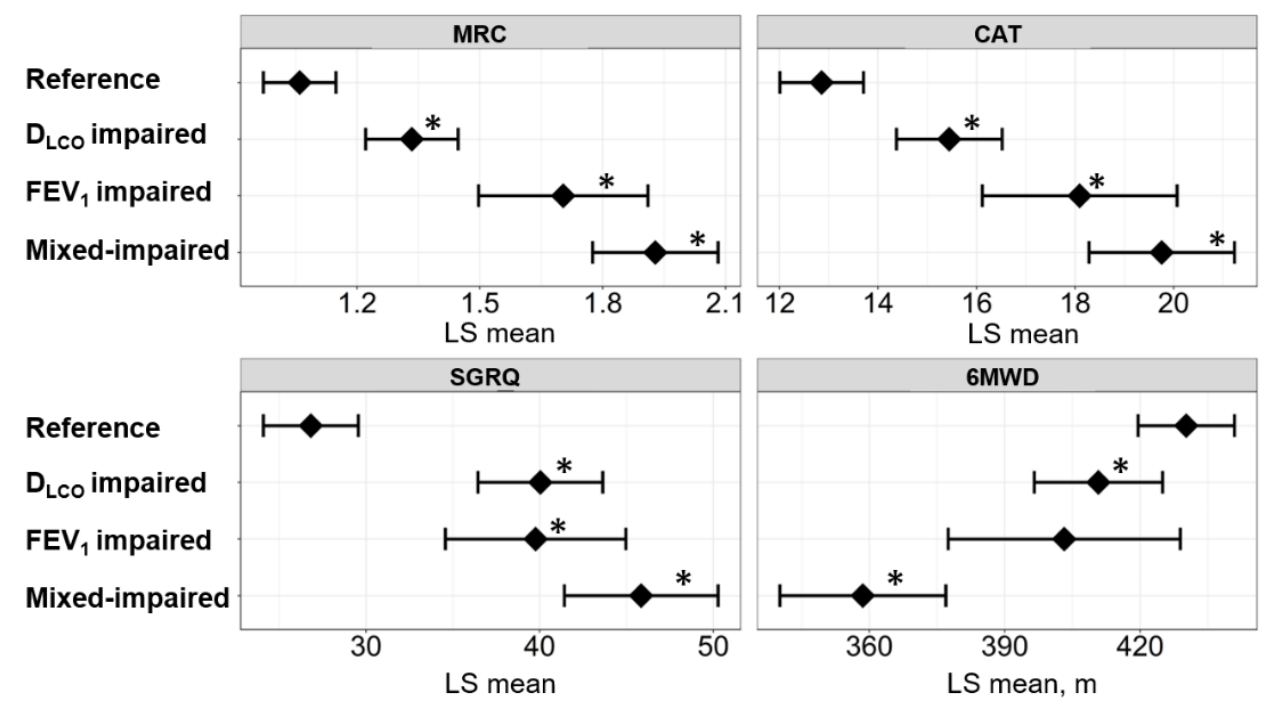




\section{Figure 4}
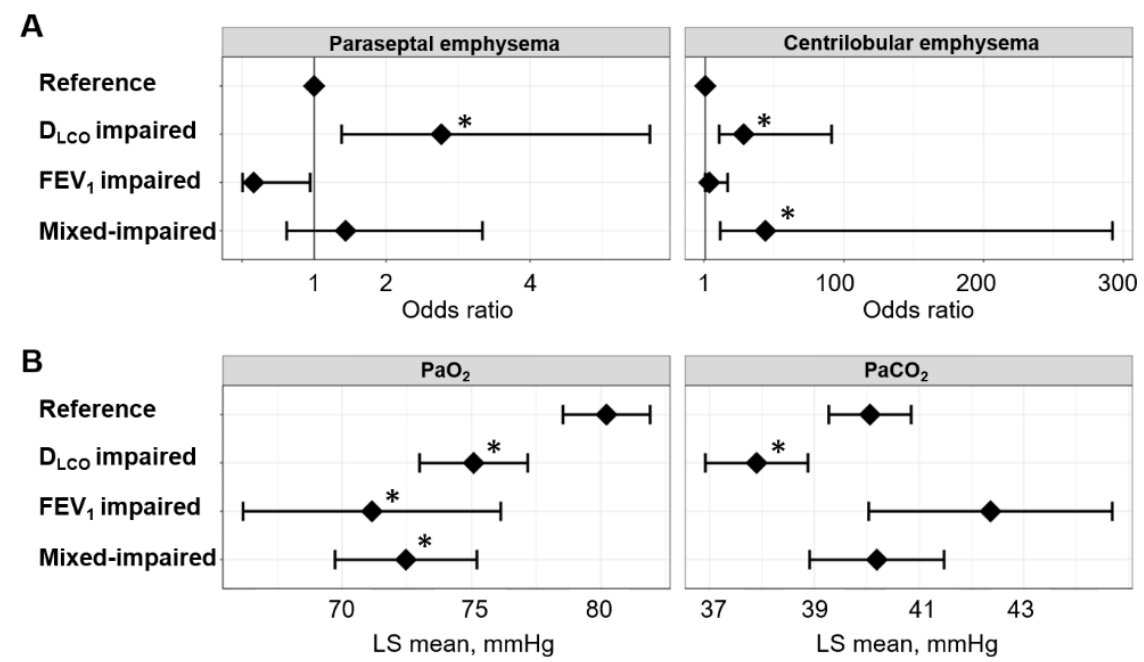


\section{Figure 5}

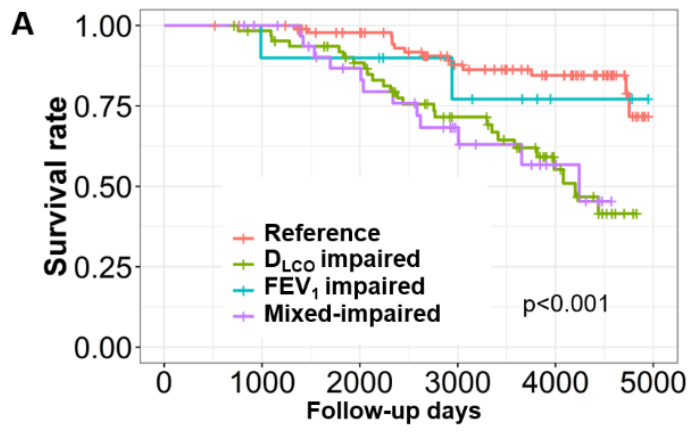

B

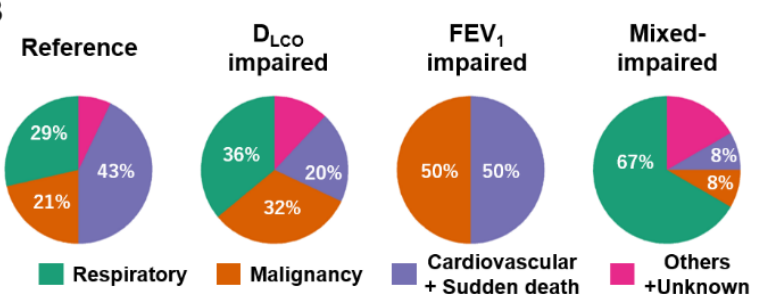

C
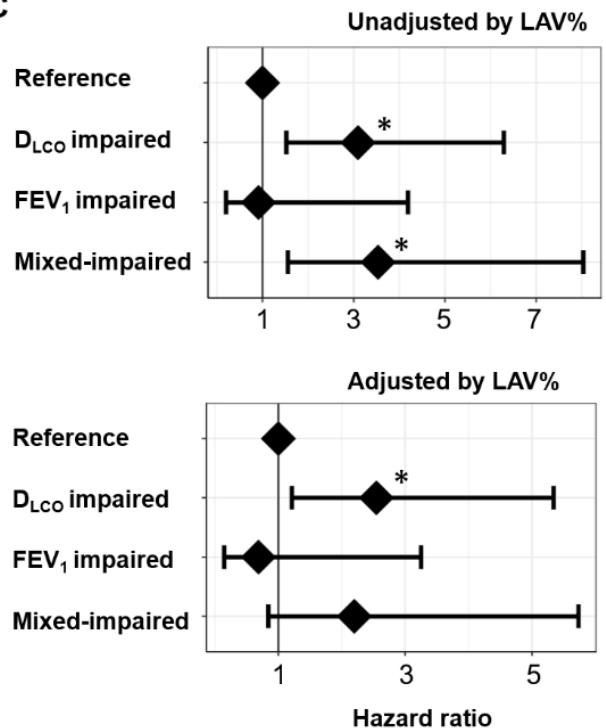